\title{
In-vitro activity of 21 antimicrobial agents against Neisseria gonorrhoeae in Brussels
}

\author{
B GORDTS, R VANHOOF, J M HUBRECHTS, R DIERICKX, H COIGNAU, AND \\ J P BUTZLER
}

From the Microbiology Laboratory, University Hospital (St Pieters), Brussels, Belgium

SUMMARY The minimum inhibitory concentrations (MIC) of 21 antimicrobial agents was measured for 80 strains of Neisseria gonorrhoeae isolated in Brussels in 1978. Bimodal distributions were found for penicillin $G$, ampicillin, amoxycillin, carbenicillin, and cephalexin. Of the strains, $17 \cdot 5 \%$ were relatively resistant to penicillin $\mathrm{G}(\mathrm{MIC}>0.08 \mu \mathrm{g} / \mathrm{ml}), 27 \cdot 5 \%$ to ampicillin (MIC >0.16 $\mu \mathrm{g} / \mathrm{ml}$ ), $23 \cdot 8 \%$ to amoxycillin, and $43 \cdot 3 \%$ to carbenicillin. Cefotaxime was the most active antibiotic, with MICs in the nanogram range; $3 \cdot 8 \%$ and $5 \%$ of the strains were relatively resistant to cephaloridine and cephalexin respectively, but no strains were resistant to cefazolin, cefuroxime, or cefotaxime. Resistance to tetracycline, doxycycline, minocycline, erythromycin, and spiramycin (MIC $>1 \mu \mathrm{g} / \mathrm{ml}$ ) was found in $6 \cdot 3 \%, 2 \cdot 5 \%, 2 \cdot 5 \%, 5 \%$, and $51 \cdot 3 \%$ of the strains respectively.

A very good correlation was present between chloramphenicol and thiamphenicol, with $16 \cdot 3 \%$ and $10 \%$ of relatively resistant strains respectively. Only two isolates showed an MIC $>1 \cdot 25 \mu \mathrm{g} / \mathrm{ml}$ for rifampicin, and $10 \%$ of the strains needed $\geqslant 12 \mu \mathrm{g} / \mathrm{ml}$ of spectinomycin for complete inhibition of growth. A very high synergy was found for the $20: 1$ combination of sulphamethoxazole and trimethoprim, with only one isolate resistant to this combination. None of the strains tested produced $\beta$-lactamase.

\section{Introduction}

Many studies have been carried out in Western Europe over the last 20 years to test the in-vitro sensitivity of Neisseria gonorrhoeae to various antimicrobial agents. A definite progression towards decreased sensitivity to various antibiotics has been noticed. ${ }^{1}$ Greater importance has been attached to the regional differences in the sensitivity patterns of gonococci. $^{23}$ It seems important, therefore, to continue screening the sensitivity of gonococci in different parts of the world. This paper describes quantitative sensitivity determinations of $\mathbf{8 0}$ unselected strains of $N$ gonorrhoeae isolated before treatment in the venereal disease clinic at the St Pieters Hospital in Brussels from 1 January to $\mathbf{3 1}$ December 1978. The results are compared with those of other workers in other regions and with those of a similar study in the same hospital in $1976 .{ }^{4}$

Address for reprints: Dr B Gordts, Microbiology Laboratory, University Hospital (St Pieters), Hoogstraat 322, B-1000 Brussels, Belgium

Accepted for publication 1 September 1981

\section{Materials and methods}

ISOLATION OF GONOCOCCAL STRAINS

Eighty strains of $\boldsymbol{N}$ gonorrhoeae were isolated from male and female patients attending the venereal diseases clinic at the St Pieters Hospital in Brussels during 1978. Immediate diagnosis was made by the examination of Gram-stained smears. The strains were cultured on selective Thayer-Martin medium and incubated at $37^{\circ} \mathrm{C}$ in $10 \% \mathrm{CO}_{2}$ for 48 hours. The organisms were identified by colonial morphology, Gram-staining, oxidase activity, and sugar fermentation. The purified cultures were suspended in sterile horse serum and stored in liquid nitrogen until investigated further.

\section{SENSITIVITY TESTING}

Antibiotic sensitivity testing was performed by a dilution method in liquid medium. The strains were cultured on a medium containing brain-heart infusion (BHI) broth (Difco 0037-01) and 1.5\% agar enriched with $10 \%$ defibrinated horse blood (Institut Pasteur, Brussels) and 1\% sterile GC supplement (Oxoid SR 56). The plates were incubated in $10 \%$ 
$\mathrm{CO}_{2}$ for 48 hours. The resulting colonies were then suspended in a Mueller-Hinton broth to give $3 \times 10^{8}$ colony-forming units (cfu)/ml (McFarland No 1).

The medium used to test the sensitivity of the antimicrobial agents was Mueller-Hinton broth to which was added 1\% Polyvitex (Bio-Merieux $5-5651), 5 \%$ of a haemin solution $(600 \mu \mathrm{g} / \mathrm{ml})(\mathrm{BDH}-$ Biochemicals 24011), and 2\% sterile horse serum. To test the sensitivity to the sulphonamides, $5 \%$ haemolysed horse blood (Institut Pasteur, Brussels) was used instead of haemin in the medium. The medium was dispensed in microtitre plates (Dynatech MA1501/N), together with two-fold dilutions of the antibiotics, by a Dynatech 96 Channel Dispenser. The test plates were inoculated with the suspension by a MIC 2000 Dynatech Inoculator which places $1 \mu \mathrm{l}$ of the suspension in every test cup of $100 \mu \mathrm{l}$, giving a final concentration of $3 \times 10^{6} \mathrm{cfu} / \mathrm{ml}$. In every test plate, one row was left without any antibiotic. Two reference strains of $\boldsymbol{N}$ gonorrhoeae (Reyn 181, Reyn 183) with known sensitivity patterns were tested simultaneously in each run. The plates were incubated in $10 \% \mathrm{CO}_{2}$ and examined after 48 hours in a Dynatech Viewbox. The lowest antibiotic concentration that inhibited bacterial growth completely, or almost completely, was regarded as the minimum inhibitory concentration (MIC).

\section{ANTIMICROBIAL AGENTS}

The following antimicrobial agents were tested: penicillin G (Continental Pharma), ampicillin (Bristol), amoxycillin and carbenicillin (Beecham Laboratories), cephaloridine, cephalexin, and cefazolin (Eli Lilly Laboratories), cefuroxime (Glaxo), cefotaxime (Hoechst), erythromycin (Abbott Laboratories), spiramycin (Specia), tetracycline HCL (Certa), doxycycline (Pfizer), minocycline (Lederle), chloramphenicol and rifampicin (Lepetit), thiamphenicol (Zambon), spectinomycin (Upjohn), trimethoprim and sulphamethoxazole (Roche SA) and a combination of sulphamethoxazole and trimethoprim in a $20: 1$ ratio.

Screening for $\beta$-lactamase production was performed by the chromogenic cephalosporin test (Glaxo compound 87/312).

\section{Results}

The distribution of the MICs for the 21 antimicrobial agents tested is shown in tables I and II. Bimodal distributions were found with penicillin G, ampicillin, amoxycillin, carbenicillin, and cephalexin (figure). Tests for $\beta$-lactamase production gave negative results for all the $\mathbf{8 0}$ strains.

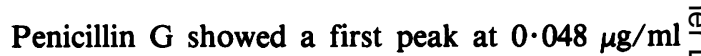
and a second at $0.012 \mu \mathrm{g} / \mathrm{ml}$. We defined relative $\frac{\mathrm{O}}{\mathrm{s}}$ resistance (RR) as an MIC $>0.08 \mu \mathrm{g} / \mathrm{ml} ; 17.5 \%$ of the strains fell into this group, and $6 \cdot 3 \%$ of the strains showed "high level resistance" to penicillin Go (MIC $>0.39 \mu \mathrm{g} / \mathrm{ml}$ ). For ampicillin the two peaks 음 occurred at 0.097 and 0.012-0.006 $\mu \mathrm{g} / \mathrm{ml}$ and $27.5 \%$ के of strains were considered to be relatively resistant $\overparen{\otimes}$ $(\mathrm{MIC}>0 \cdot 16 \mu \mathrm{g} / \mathrm{ml}$ ).

The peaks for amoxycillin were at 0.195-0.097 के $\mu \mathrm{g} / \mathrm{ml}$ and $0.012-0.006 \mu \mathrm{g} / \mathrm{ml} ; 23.8 \%$ of the strains $\vec{\circ}$ were RR. Carbenicillin showed peaks at $0 \cdot 195 \mu \mathrm{g} / \mathrm{ml} \overrightarrow{\vec{C}}$ and $0.006 \mu \mathrm{g} / \mathrm{ml} ; 43.3 \%$ were RR. A bimodal ${ }_{\sigma}^{\omega}$ distribution was also found for cephalexin, with a first modus at $0 \cdot 195-0 \cdot 39 \mu \mathrm{g} / \mathrm{ml}$ and a second at $1.56 \mathrm{G}$ $\mu \mathrm{g} / \mathrm{ml}$. For the second modus strains of cephalexin ${ }_{-}^{\infty}$ only five out of 23 were also RR to penicillin $G$, while $\overrightarrow{\text { N }}$ 10 strains were RR to ampicillin, nine to amoxycillin, $\omega$ and 15 to carbenicillin.

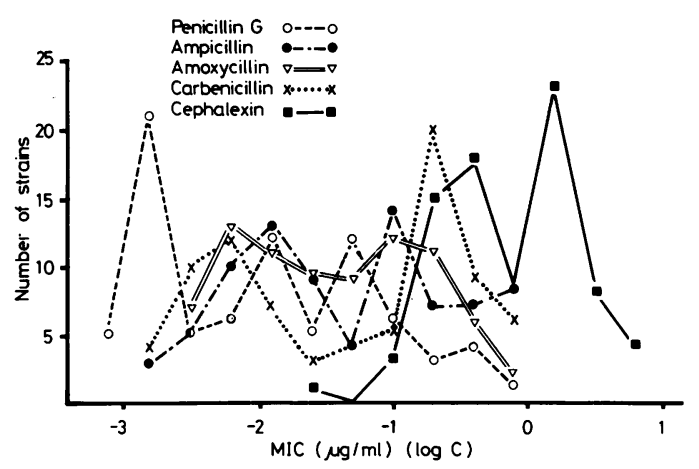

FIGURE Distribution of MICs for penicillin $G$, ampicillin, amoxycillin, carbenicillin, and cephalexin.

For the cephalosporins $3.8 \%$ of the strains were RR to cephaloridine (MIC $>3 \cdot 12 \mu \mathrm{g} / \mathrm{ml}$ ), while $5 \%$. were $R R$ to cephalexin. All were sensitive to cefazolin, cefuroxime, and cefotaxime. Among the tetracyclines, doxycycline and minocycline showed $a_{\circ}$

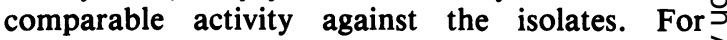
tetracycline, doxycycline, and minocycline $\frac{D}{0}$ respectively $6 \cdot 25,2 \cdot 5$, and $2 \cdot 5 \%$ of the isolates were RR (MIC $>1 \mu \mathrm{g} / \mathrm{ml})$. Two isolates that were RR to $\tilde{\sigma}$ tetracycline were also $R R$ to penicillin $G$, while $N$ among the 14 strains that were $R R$ to penicillin $G \stackrel{N}{N}$ only two were also RR to tetracycline.

Both chloramphenicol and thiamphenicol showed ${ }^{\circ}$ a peak at $0 \cdot 195 \mu \mathrm{g} / \mathrm{ml} ; 16 \cdot 3 \%$ of the strains were $R R^{\circ}$ to chloramphenicol and $10 \%$ to thiamphenicol. Erythromycin was more active than spiramycin, with only $5 \%$ being RR to it, while $51 \cdot 3 \%$ were RR to $\frac{T}{\circ}$ spiramycin. For rifampicin two strains required $\frac{\vec{D}}{\mathbb{D}}$ $50 \mu \mathrm{g} / \mathrm{ml}$ or more to inhibit growth, but all the others $\stackrel{\oplus}{\overparen{D}}$ $(97 \cdot 5 \%)$ were sensitive. 


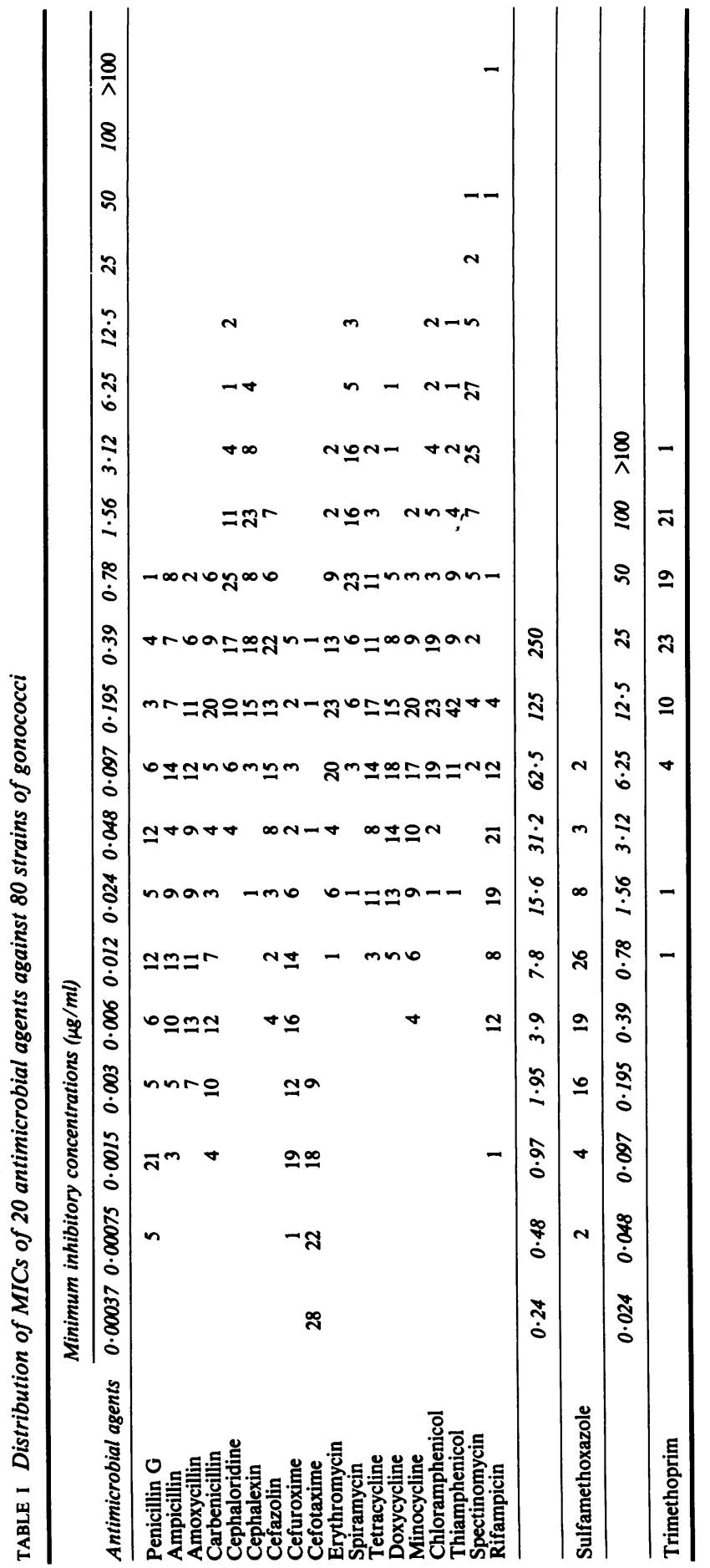


TABLE II Minimum inhibitory concentration of $20: 1$ combination of sulphamethoxazole and trimethoprim

\begin{tabular}{|c|c|c|c|c|c|c|c|c|c|}
\hline \multirow[b]{2}{*}{ Trimethoprim $(\mu / \mathrm{ml})$} & \multicolumn{9}{|c|}{ Sulphamethoxazole $(\mu \mathrm{g} / \mathrm{ml})$} \\
\hline & $0 \cdot 12$ & $0 \cdot 24$ & 0.48 & 0.97 & 1.95 & $3 \cdot 9$ & $7 \cdot 8$ & $15 \cdot 6$ & $31 \cdot 2$ \\
\hline $\begin{array}{l}0.006 \\
0.012 \\
0.024 \\
0.048 \\
0.097 \\
0.195 \\
0.39 \\
0.78 \\
1.56\end{array}$ & 1 & 1 & 1 & 3 & 17 & 31 & 22 & 3 & 1 \\
\hline
\end{tabular}

Ten per cent of the strains needed $12 \mu \mathrm{g} / \mathrm{ml}$ of spectinomycin for complete inhibition of growth. With the sulphonamides $51 \cdot 3 \%$ were $R R$ to trimethoprim (MIC $>25 \mu \mathrm{g} / \mathrm{ml}$ ) and $6 \cdot 3 \%$ to sulphamethoxazole (MIC $>15.6 \mu \mathrm{g} / \mathrm{ml}$ ). The $20: 1$ combination of sulphamethoxazole and trimethoprim resulted in a significant reduction in the MICs.

The number of strains that were cross-resistant with penicillin $G$ are shown in table III. We found no multiresistant strains. The contingency coefficient $C$, which measures the extent of correlation between two sets of attributes and is computed from $2 \times 2$ contingency table for all pairs of antimicrobial agents, is given in table IV. The significance of the C factor is tested by the $\chi^{2}$ test. $^{5 a}$

A very good correlation was found between the different penicillins and the cephalosporins. Only penicillin $G$ and ampicillin showed a correlation with cephalexin. The penicillins also had a poor correlation with the tetracyclines, except for amoxycillin, which showed a slightly better

TABLE III Strains relatively resistant to penicillin $G$ which showed cross-resistance to other antibacterial agents*

\begin{tabular}{lcc}
\hline & \multicolumn{2}{l}{ Strains } \\
\cline { 2 - 3 } Antimicrobial agents & No & $\%$ \\
\hline Ampicillin & 9 & $64 \cdot 3$ \\
Amoxycillin & 8 & $57 \cdot 1$ \\
Carbenicillin & 11 & $78 \cdot 6$ \\
Cephaloridine & 1 & $7 \cdot 1$ \\
Cephalexin & 3 & $21 \cdot 4$ \\
Cefazolin & 0 & 0 \\
Cefuroxime & 0 & 0 \\
Cefotaxime & 0 & 0 \\
Erythromycin & 4 & $28 \cdot 6$ \\
Spiramycin & 13 & $92 \cdot 9$ \\
Tetracycline & 2 & $14 \cdot 3$ \\
Doxycycline & 1 & $7 \cdot 1$ \\
Minocycline & 0 & 0 \\
Chloramphenicol & 6 & $42 \cdot 9$ \\
Thiamphenicol & 4 & $28 \cdot 6$ \\
Spectinomycin & 5 & $35 \cdot 7$ \\
Rifampicin & 0 & 0 \\
Trimethoprim & 5 & $35 \cdot 7$ \\
Sulphamethoxazole & 1 & $7 \cdot 1$ \\
Co-trimoxazole & 0 & 0 \\
\hline t14 & 0 & \\
\hline
\end{tabular}

*14 strains relatively resistant to penicillin G $(\mathrm{MIC}>0.08 \mu \mathrm{g} / \mathrm{ml})$ correlation with the tetracyclines. No correlation was $\stackrel{\vec{\omega}}{\mathscr{\omega}}$ found between the different cephalosporins, except $\stackrel{\rho}{=}$. for a slightly better correlation between cephalexin जั and cephaloridine.

Erythromycin showed a poor correlation with $\tilde{\omega}_{\tilde{S}}$ spiramycin, and no correlation with the differento tetracyclines. Tetracycline showed a good correlation with doxycycline and minocycline, but there was no $\rightarrow$ correlation between the two latter antibiotics. The $\frac{\mathbb{D}}{\circ}$ correlation between chloramphenicol and thiamphenicol was excellent. Rifampicin showed no: correlation with any other antibiotic. This was also $\vec{\theta}$ found for sulphamethoxazole; a correlation was only $\stackrel{\infty}{\circ}$ found between co-trimoxazole and sulpha-: methoxazole but not between the sulphonamides and any other of the antimicrobial agents tested.

\section{Discussion}

The results for penicillin $G(17 \cdot 5 \% R R)$ show that there has been a marked decrease in the proportion $\frac{O}{3}$ of RR strains of $N$ gonorrhoeae since the study of $\tau$ Vanhoof et al, ${ }^{4}$ in which $51 \%$ of the strains were RR. Meheus et $a l^{\mathrm{b}}$ found a similar result as in the present study. A decrease in RR strains has already been described by Olsen and Lomholt ${ }^{6}$ in Greenland and by Seth and Wilkinson ${ }^{7}$ in London. For ampicillin, we found that $27.5 \%$ of the strains were RR. This is a lower percentage than that reported by Meheus et $a l,{ }^{5 b}$ and much lower than in the former study of Vanhoof $e t$ al in Brussels. ${ }^{4}$

The other penicillins (amoxycillin and carbenicillin) also showed a lower proportion of $R R$ strains than reported in the former Belgian studies. For cephalexin, a bimodal distribution was obvious, but only $17 \%$ of the second modus strains were also $\omega$ RR to penicillin $G$ in contrast to the former study of ${ }^{-}$ Vanhoof $e t a l,{ }^{4}$ in which all second modus strains of $\stackrel{\circ}{C}$ cephalexin were found to be RR to penicillin G.

In general, very good sensitivity was found for the new cephalosporins, with no RR strains at all and all ${ }^{\circ}$ MICs $>0.78 \mu \mathrm{g} / \mathrm{ml}$. Cefotaxime was the most active $\stackrel{\overrightarrow{\mathrm{D}}}{\mathrm{O}}$ of all the antibiotics tested in this study. We found $\cong$ that $6 \cdot 3 \%$ of the strains were RR to tetracycline, $\stackrel{\square}{\square}$ 


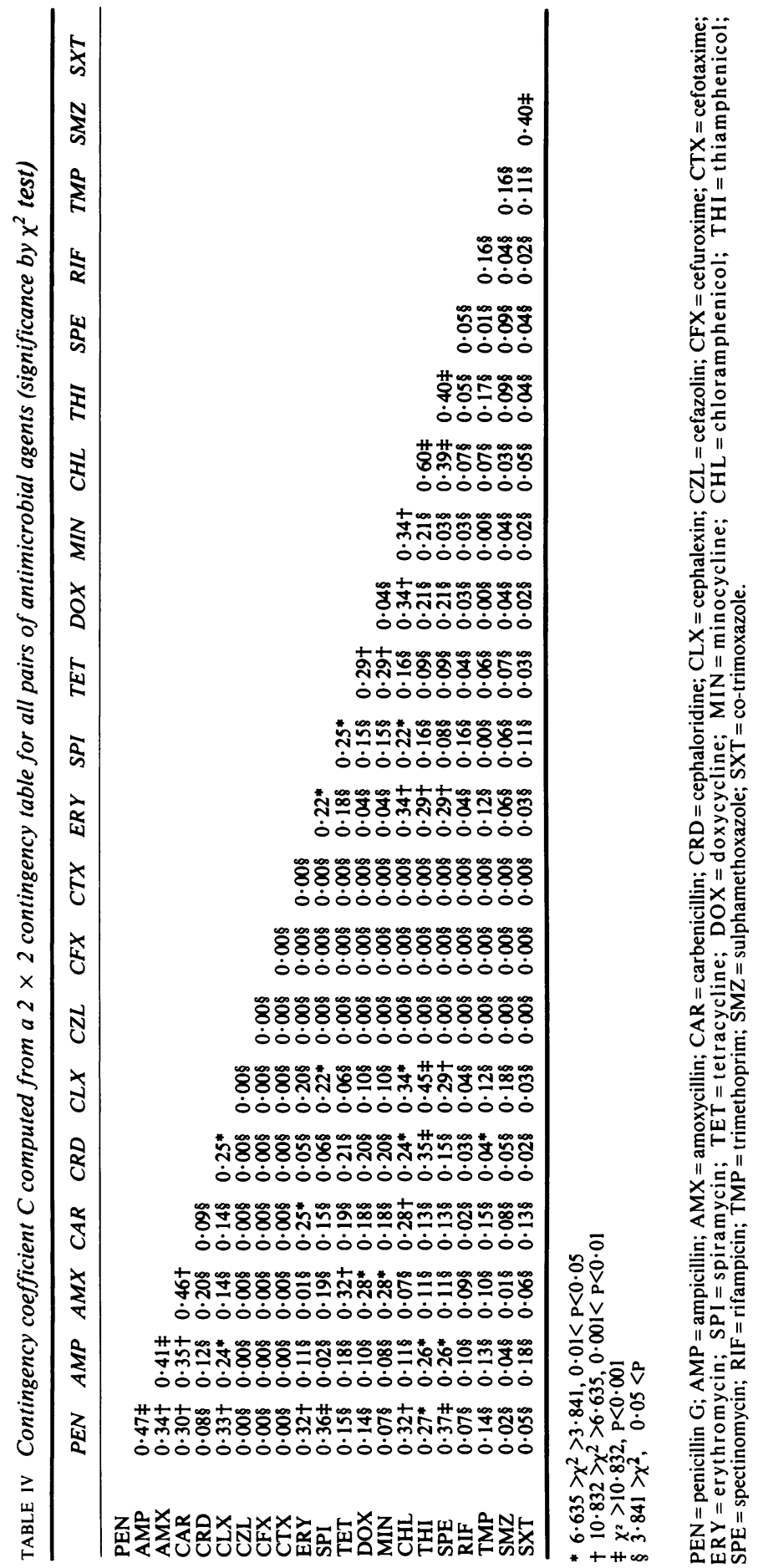


which is very low compared with the studies of Stolz and Zwart, ${ }^{2}$ Bergogne-Berezin, ${ }^{1}$ Meheus et al, ${ }^{\text {sb }}$ and Jaffe et al. ${ }^{3}$ Doxycycline and minocycline showed comparable activity. Five per cent of the strains seemed to be RR to erythromycin, which is greater than that found by Meheus. ${ }^{4}$ Robson and Salit, ${ }^{8}$ and Givan and Keyl.9 Erythromycin showed a much higher activity than spiramycin. Ten per cent of the strains needed $\geqslant 12 \mu \mathrm{g} / \mathrm{ml}$ of spectinomycin to be inhibited. This seems to be high in comparison with other studies. Only about $2 \cdot 5 \%$ of the strains were RR to rifampicin, and this agrees well with former results. Once again, the synergy between sulphamethoxazole and trimethoprim was noticed. Only one strain showed relative resistance to the 20:1 combination.

We did not find any $\beta$-lactamase-producing gonococcal strains in our population; these strains are extremely rare in Belgium. ${ }^{10}$

\section{References}

1. Bergogne-Berezin E, Zechovsky N, Siboulet A. Sensibilité actuelle de Neisseria gonorrhoeae. Etude de 100 souches dans la région Parisienne. Sem Hop Ther 1975;51:81-90.
2. Stolz E, Zwart HGF, Michel MF. Activity of eight antimicrobial agents in vitro against Neisseria gonorrhoeae. $\mathrm{Br}$ $J$ Vener Dis, 1975; 51:257-64.

3. Jaffe $\mathrm{HW}$, Biddle JW, Thornsberry $\mathrm{C}$, et al. National gonorrhoea therapy monitoring study. In-vitro antibiotic $\Rightarrow$ susceptibility and its correlation with treatment results. $\omega$ N Engl J Med, 1976;294:5-9.

4. Vanhoof R, Vanderlinden MP, Hubrechts JM, Butzler JP, Yourassowsky E. In-vitro activity of antimicrobial agents against Neisseria gonorrhoeae in Brussels. $\mathrm{Br} J$ Vener Dis 1976;52:197-8.

5a. Siegel S. Non-parametric Statistics for the Behavioral Sciences. New York: McGraw-Hill-Kogakusha, 1956; 196-202.

5b. Meheus A, Piot P, Pattyn S, Van Dyck E, Vanden Berghe D. Activity in vitro of 10 antimicrobial agents against Neisseria gonorrhoeae. A study of the correlation between the. sensitivities. Br J Vener Dis 1976; 52: 329-32.

6. Olson GA, Lomholt $G$. Gonorrhoea treated by a combination $\vec{\omega}$ of probenecid and sodium penicillin $\mathrm{G} . \mathrm{Br} J$ Venero Dis 1969;45: 144.

7. Wilkinson AE. The sensitivity of gonococci to penicillin. $J \stackrel{O}{=}$ Antimicrob Chemother 1977;3:197-8.

8. Robson HG, Salit IE. Susceptibility of Neisseria gonorrhoeae. to seven antibiotics in vitro. Can Med Assoc $J$. 1972; 107:959-62.

9. Givan KF, Keyl A. Antibiotic sensitivities of Neisseria ${ }^{\omega}$ gonorrhoeae in the Toronto area. Can Med Assoc $J$ 음 1974: 111:44-6.

10. Piot P. Resistant gonococcus from the Ivory coast. Lancet $1977 ; \mathrm{i}: 857$ 